\title{
El tanino vegetal. Aprovechamiento y usos de la nuez de agalla en la España bajomedieval
}

\author{
Vegetable tannin. Exploitation and uses of the gallnut \\ in late medieval Spain
}

Javier LÓPEZ RIDER

\begin{abstract}
Author:
Javier López Rider

Profesor Ayudante Doctor. Departamento de Historia. Universidad de Córdoba (Córdoba, Spain)

lopezrider@uco.es

https://orcid.org/0000-0002-8412-921X

Date of reception: 29/03/21

Date of acceptance: 11/06/21

Citation:

López Rider, J. (2021). El tanino vegetal. Aprovechamiento y usos de la nuez de agalla en la España bajomedieval. Anales de la Universidad de Alicante. Historia Medieval, (22), 219-245.

https://doi.org/10.14198/medieval.19489

Funding: El presente trabajo ha sido realizado en el marco del proyecto PID2019108736GB-I00. Pruévalo e verás ques çierto. Recetas y conocimientos de la sociedad medieval para el siglo XXI, financiado por la Agencia Estatal de Investigación, Ministerio de Ciencia e Innovación.

C 2021 Javier López Rider

Licence: This work is licensed under a Creative Commons Attribution 4.0 International License (CC BY 4.0).
\end{abstract}

\section{RESUMEN}

El presente trabajo analiza la utilización que tuvo la agalla vegetal en España durante los siglos bajomedievales. Este recurso natural, extraído de diferentes árboles, especialmente robles y encinas, entre otros, solía triturarse para usarse en pequeños trozos o en forma de polvo para varios procedimientos técnicos. A veces, de manera previa y para obtener el mayor beneficio posible, era común que se llevara a cabo su disolución en determinados líquidos como agua, aceite de oliva o vino, según el producto que se deseara elaborar. A continuación, la mezcla solía hervirse al fuego o mantenerse al sol para su secado, con la posibilidad de combinarse después con otros componentes. Gracias a su alto contenido en ácido tánico y gálico, permitió que se empleara para obtener el color negro en tintas de escritura ferrogálicas, como curtiente en pieles y como mordiente y tinte en la industria textil, con relevancia en la seda, pero tuvo otras finalidades en ámbitos como la medicina (para afecciones bucales, estomacales y hemorragias) y cosmética (teñir y ocultar el blanco de las canas de cabellos y barbas, blanquear los dientes o combatir la alopecia). Fue un ingrediente fundamental para varias industrias $y$, por sus propiedades, para la sociedad en general. Una realidad que queda 
reflejada por su elevado consumo, pero también por su comercialización a través de todo el Mediterráneo Oriental.

PALABRAS CLAVE: recetarios; medio natural; baja Edad Media; saber técnico; comercio.

\section{ABSTRACT}

This paper analyzes the use of vegetable galls in Spain during the Late medieval centuries. This natural resource, extracted from different trees, especially oaks and holm oaks, among others, used to be crushed to be used in small pieces or in powder form for various technical procedures. Sometimes, beforehand and to obtain the greatest possible benefit, it was common to dissolve it in certain liquids such as water, olive oil or wine, depending on the product to be elaborated. Afterwards, the mixture was usually boiled over a fire or kept in the sun to dry, with the possibility of combining it with other components. Thanks to its high content of tannic and gallic acid, it was used to obtain the black colour in iron-gallic writing inks, as a tanning agent in leather and as a mordant and dye in the textile industry, with relevance in silk, but it had other purposes in areas such as medicine (for oral and stomach ailments and bleeding) and cosmetics (to dye and hide the white of gray hair and beards, whiten teeth or combat alopecia). It was a fundamental ingredient for several industries and, due to its properties, for society in general. A reality that is reflected by its high consumption, but also by its commercialization throughout the Eastern Mediterranean.

KEYWORDS: recipe Books; natural environment; Late Middle Ages; technical knowledge; trade.

\section{INTRODUCCIÓN}

En todo el amplio territorio de la España bajomedieval, existió un claro e intenso aprovechamiento de los recursos forestales que la naturaleza ofrecía, una explotación documentada y previa a la etapa medieval, como se ha manifestado en algunos de los trabajos publicados hasta el momento sobre la temática (Pérez Embid, 2002; Clemente Ramos, 2002; Vignet Zunz y Ortega Santos, 2003; Martín Gutiérrez, 2007, pp. 121-150; García de Cortázar, 2002, pp. 15-42 y 2007, pp. 251-274, entre otros). El disfrute de estas materias primas no era exclusivamente para la vida doméstica, sino también para proveer de lo necesario a la industria, que requería de energía térmica (leña y carbón) (López Rider, 2016, pp. 819-858) y determinadas materias primas para la elaboración de diversos productos (sustancias tintóreas, colorantes, resinas, gomas, curtientes, etc.) (Sesma Muñoz, 2001, pp. 195-213; Cabrera Muñoz, 2002, pp. 249-272; Córdoba de la Llave, 2002, pp. 243-254 y Carmona Ruiz, 2011, p. 194). 
Entre los recursos que la propia naturaleza ofrecía en el ámbito rural, destaca la nuez de agalla, localizada en diferentes especies arbóreas e identificada en la época a través de las fuentes documentales. La mayoría de las referencias a esta materia vegetal procede de los denominados recetarios, manuscritos en cuyo interior se recogen recopilaciones de numerosas recetas artesanales de temática variada. Gracias a su contenido, se mencionan las sustancias que se emplean, las cantidades de esos ingredientes y el método de trabajo a aplicar. En este estudio, se analizará la importancia que tuvo la nuez de agalla en la Península Ibérica que, gracias a su alto porcentaje en taninos, se usó para la fabricación de tintas de color negro de tipo ferrogálico, como curtiente en pieles, mordiente y tinte de tejidos y como ingrediente principal en varios tratamientos médicos y cosméticos.

\section{LA AGALLA VEGETAL COMO RECURSO NATURAL}

La nuez de agalla, denominada en época árabe asfa o algazafán (Maíllo Salgado, 1998, p. 255 y Carabaza Bravo, 1999, pp. 34-35) y en las fuentes escritas bajomedievales como gala, galla o nuez de agalla, se trata de una excrecencia que se origina en varias especies de árboles a través de la picadura de diversos insectos que depositan sus huevos en ramas y hojas, aunque el más habitual es el Cynips tinctoria y todos sus subgéneros (Darwin, ed. de 2008, pp. 738-741; Córdoba de la Llave, 2005, p. 31). En un estudio de 1998, Nieves-Aldrey las define como "estructuras anormales de parte de los tejidos u órganos de las plantas que se desarrollan por la reacción específica a la presencia o actividad de un organismo inductor (planta o animal, normalmente un insecto)", causando la morfología anormal que suelen obtener estas agallas (Nieves-Aldrey, 1998, p. 3). En función del tipo de árbol y el insecto que participa en todo el proceso indicado, la nuez de agalla es de diferente morfología, composición y propiedades. Esto genera que se aluda a agallas de colores más claros, a veces con rugosidades, de tamaño y calidad variables (Contreras Zamorano, 2015, p. 230 y ss.). Las agallas más conocidas provienen del género Quercus, especialmente robles y encinas (Segura Munguía y Torres Ripa, 2009, p. 152) y de diferentes lugares como Turquía, Norte de África o Europa como las de Istria, Francia, Hungría, Bohemia, Flandes, Italia o España (Quercus ilex rotundifolia, Quercus coccifera, Quercus ilex). Eran famosas las procedentes de Esmirna, Mosul, Basora y Alepo (Grégorie y Desplats, 1894, p. 49; Contreras Zamorano, 2015, pp. 230-233 y p. 335; López Rider, 2018, pp. 364-384). Gracias a las referencias comerciales, especialmente de la Corona de Aragón, se nombran algunas variedades de agallas: las ya citadas de Alepo (Siria) y Chipre (Turquía), de la China, de Rumanía, de Vallnegra, del Golfo (mar Adriático), de Poniente, de Túnez, de Apulia (Italia), la mezclada y la grosa y menuda de Levante (Pifarré Torres, 2002, pp. 212-213; Melis, 1972, p. 312 y p. 320 y Gual Camarena, 1981, p. 129, VIII, 68; p. 172, XV, 41 y pp. 203-204, XVI, 23- 
24). En ocasiones se alude a su calidad, señalándose que la mejor es la de Rumanía seguida por la de Vallnegra y la mezclada (Gual Camarena, p. 101, IV, 18-20).

En todo caso, lo que hace significativa la agalla vegetal es su alto contenido en ácido tánico y gálico. Cuando el insecto nace en su interior y se marcha dejando un pequeño orificio, es cuando las agallas quedan vacías y ricas en tanino (De Hamel, 2001, pp. 32-33 y García Marsilla, 2017, p. 299). Sin embargo, M. Zerdoun, en su estudio sobre las tintas negras en época medieval, recoge que cuando el insecto abandona la agalla, es más ligera y posee menos cantidad de tanino (Zerdoun BatYehouda, 1983, pp. 342-343). De un modo u otro, la verdad que era muy preciada para diferentes utilidades, como obtener tintas de escritura, para curtir pieles y teñir fibras textiles, cabellos y barbas o para curar ciertas afecciones (Grégorie y Desplats, 1894, p. 49; Córdoba de la Llave, 2002, p. 246; Criado Vega, 2013, pp. 467-469 y García Marsilla, 2017, p. 299). De hecho, antes del período medieval, existen referencias sobre la nuez de agalla en autores como Teofrasto, que destaca el elevado porcentaje de taninos en roble silvestre (Teofrasto, ed. de 1988, p. 79). Incluso hace una diferenciación entre agallas blancas y negras, matizando que el roble hemerís produce unas agallas de gran calidad para el curtido de pieles (Teofrasto, ed. de 1988, Libro III, capítulo V, p. 165 y capítulo VIII, p. 178).

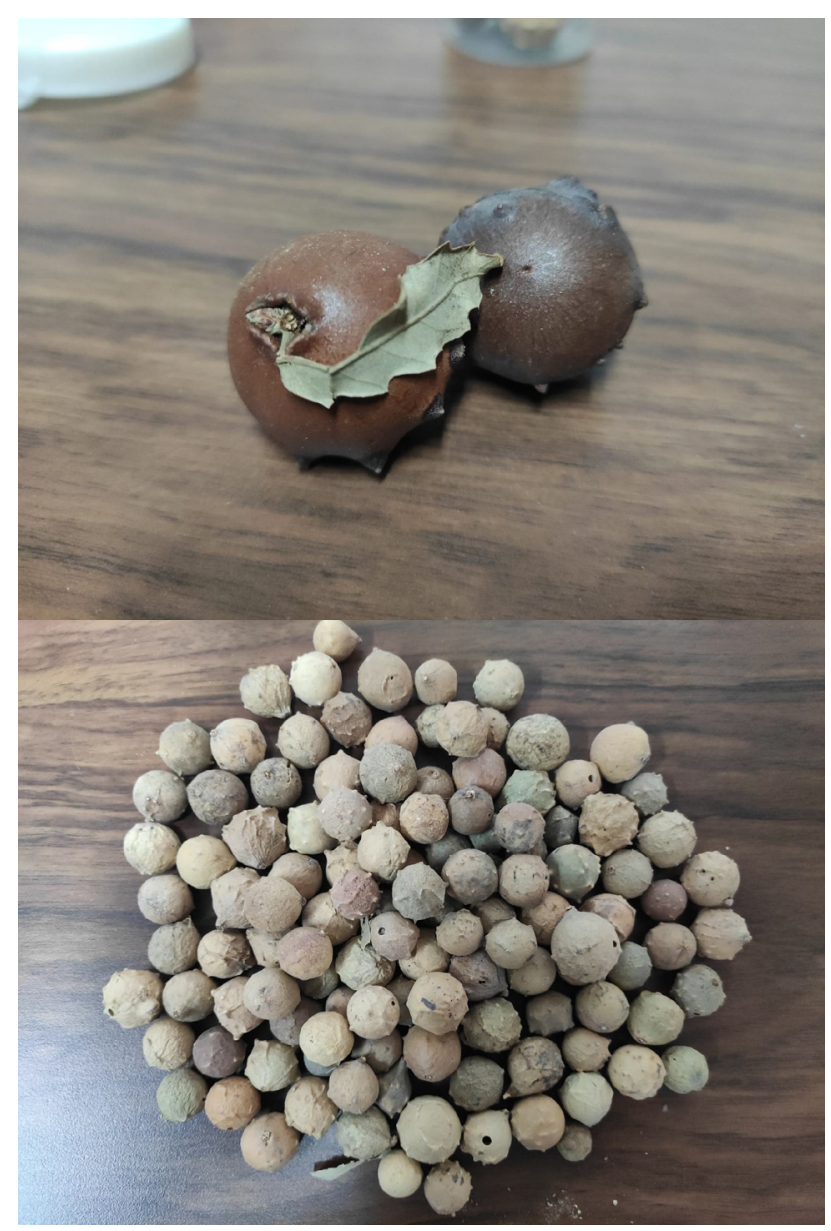

Fig. 1. Diferentes tipologías de agallas de roble. (Fotografías propias del autor). 
También menciona, con menor importancia, las agallas de la coscoja, al considerarlas de peores propiedades (Teofrasto, ed. de 1988, Libro III, capítulo XVI, p. 203). Otros como Horacio y Dioscórides siguen la línea trazada por Teofrasto y dedican una parte de sus obras a hablar de las agallas. El primero, indica que todos los árboles que producen bellotas a la par crean agallas de tinte, enfatizando que la encina de bellota dulce es la que aporta las más adecuadas para el curtido de cueros, mientras que la encina de hojas anchas origina una agalla negra que es la idónea para teñir lanas (Segura Munguía y Torres Ripa, 2009, p. 155). Respecto a Dioscórides, en el libro I de su obra De materia médica menciona la agalla del roble, concretamente la denominada omphakitis, que por sus propiedades astringentes la hacen muy eficaz para diferentes problemas de salud (Dioscórides, ed. de 1998, Libro I, p. 209). Por su parte, Plinio el Viejo, en su Historia naturalis especifica lo ya recogido en Horacio, añadiendo que la agalla negra es mejor y de mayor tamaño que la blanca (Zerdoun Bat-Yehouda, 1983, pp. 342-343).

\section{USOS Y APLICACIONES}

El conocimiento que se tenía en la Antigüedad clásica sobre la nuez de agalla es transmitido para la época medieval, pues ya en el siglo $\mathrm{X}$ se tiene constancia de su utilización en el Próximo Oriente y Norte de África (Kroustallis, 2002, p. 101 y Zerdoun Bat-Yehouda, 1983, pp. 123-124). Esto alcanzó también a la Península Ibérica gracias a su vinculación con el mundo árabe y así lo reflejan las fuentes documentales bajomedievales, especialmente la literatura técnica consultada. Se aprecia que todavía para fines de la Edad Media, se continuaba empleando estas nueces para diferentes aplicaciones, y un claro ejemplo son las compraventas comerciales de esta materia prima en forma de bolas (Fig. 1).

La agalla está presente desde las primeras décadas del siglo XIII en la Corona de Aragón, según los registros de lezdas del tráfico comercial de la zona y recogidos en la tabla 1. Si bien es verdad que no se trata de un producto principal, ni uno de los más importantes, se menciona constantemente junto a otras materias primas. Al menos desde 1222 se documenta en Barcelona y alrededores, como Mediona, Tortosa, Tarragona o Cambrils, continuando todavía su comercialización en el siglo XV. También desde fechas tempranas aparece en el territorio del Reino de Valencia, desde la propia ciudad valenciana hasta lugares como Alzira, Burriana, Sagunto (Murviedro), Játiva y Biar, regulaban el precio de la carga de agallas. Por su parte, en Zaragoza para fines del siglo XIII se documenta el coste del peaje en función de la cantidad de agallas. El particular caso de Colliure ha sido incluido ya que mantuvo una estrecha vinculación con la zona aragonesa. Primero, porque sus aranceles de lezda sirvieron de modelo para fijar los de Tortosa y, en segundo lugar, el beneficio económico de Colliure se destinaba a Mallorca para 1297 (Gual Camarena, 1976, 
p. 162, XXIV, 21). Conforme se avanza en el tiempo el producto se va encareciendo junto a otras sustancias vegetales y minerales, aunque la llegada de agallas desde el comercio internacional seguía siendo constante durante los siglos posteriores.

Tabla 1. Relación de las agallas registradas en los aranceles de lezdas del territorio de la Corona de Aragón en el siglo XIII (Elaboración propia del autor).

\begin{tabular}{|c|c|c|c|}
\hline FECHA & LEZDAS & PRODUCTO & PRECIO $^{1}$ \\
\hline $1222^{2}$ & Mediona (Barcelona) & Carga de gala & 2 solidos \\
\hline $1243^{3}$ & Puerto de Tarragona & Carga de gala & - \\
\hline $1243^{4}$ & Valencia & Carga de gala & 5 solidos \\
\hline $1249^{5}$ & Colliure (Rosellón) & Carga de gala & 2 solidos, 2 dineros \\
\hline $1250^{6}$ & Alzira (Valencia) & Carga de gala & 6 denarios \\
\hline $1251^{7}$ & $\begin{array}{c}\text { Burriana, Sagunto (Murviedro), } \\
\text { Játiva y Biar (Valencia) }\end{array}$ & Carga de galle & 2 solidos, 6 denarios \\
\hline $1252^{8}$ & Tortosa (Tarragona) & Carga de gala & 2 solidos \\
\hline $1252^{9}$ & Colliure (Rosellón) & Carga de gala & 2 solidos \\
\hline $1258^{10}$ & Cambrils (Tarragona) & Carga de gala & 3 denarios \\
\hline $1271^{11}$ & Valencia & Carga de gala & 5 solidos \\
\hline $1271^{12}$ & Valencia & Carga de gala & 5 solidos/10 dineros \\
\hline $1271^{13}$ & Barcelona & Carga de gala & $\begin{array}{l}6 \text { dineros del comprador, } 6 \\
\text { del vendedor y } 6 \text { de "reva" }\end{array}$ \\
\hline $1292^{14}$ & Zaragoza & Carga de gala & $\begin{array}{c}3 \text { solidos la carga, } 3 \text { dineros } \\
\text { la arroba }\end{array}$ \\
\hline $1297^{15}$ & Colliure (Rosellón) & Carga de gala & 2 solidos \\
\hline
\end{tabular}

1 El solido (sueldo) equivale a 12 dineros, para la zona aragonesa se trata de los sueldos jaqueses (Navarro Espinach, 2009, p. 415).

2 Gual Camarena, 1976, p. 57, I, 2.

3 Gual Camarena, 1976, p. 68, II, 14.

4 Gual Camarena, 1976, p. 71, III, 31.

5 Gual Camarena, 1976, p. 75, IV, 19. Se incluye porque sirvió de modelo para el caso de Tortosa.

6 Gual Camarena, 1976, p. 89, VI, 28.

7 Gual Camarena, 1976, p. 92, VII, 31.

8 Gual Camarena, 1976, p. 96, VIII, 24; p. 137, XV, 23 y p. 170, XXV, 25. Las dos últimas referencias son versiones posteriores de la lezda de 1252.

9 Gual Camarena, 1976, p. 103, IX, 24.

10 Gual Camarena, 1976, p. 111, XI, 9.

11 Gual Camarena, 1976, p. 115, XII, 48.

12 Gual Camarena, 1976, p. 121, XIII, 49 y p. 124, XIII, 112. Otra referencia para el mismo año de Valencia señala: "Carga cotonis, gale, roye, orpimenti, cere: decem denarios", p. 117, XII, 104.

13 Gual Camarena, 1976, p. 129, XIV, 39.

14 Gual Camarena, 1976, p. 153, XIX, 17; p. 155, XIX, 103 y Navarro Espinach, 2009, p. 415.

15 Gual Camarena, 1976, p. 162, XXIV, 21. Los aranceles de la lezda de este lugar, se percibían en Mallorca. 
En relación con los datos anteriores, hay que mencionar el comercio de importación, nuevamente en la Corona de Aragón. La mayoría de las agallas pertenecen al Mediterráneo Oriental. Ese comercio internacional reside en Italia, llegando grandes cantidades de "gala" a la Península Ibérica como demuestra la documentación de la Compañía Datini en Barcelona, Mallorca o Valencia, al proceder muchas de las cargas de Venecia para el siglo XIV (Orlandi, 2008, p. 39 y Pifarré Torres, 2002, pp. 212-213). Por ejemplo, en 1383 se hace una valoración de las mercancías en Barcelona para la Compañía Datini de Florencia, nombrándose la agalla de Rumanía, y en 1398 de Venecia a Mallorca llegaron 16 kilos de agallas junto a otros productos (Melis, 1972, p. 312 y p. 322).

Para el siglo XV se mantiene ese flujo comercial, por ejemplo, en 1400, se produjo la detención en Cagliari del mercader valenciano Bernat Justafreu, al llevar su barco cargado de agalla y alumbre para exportar hacia Flandes (García Marsilla, 2017, p. 299). Dentro de esos registros, destaca el impuesto especial que se le aplicaba a ciertos productos que salían del Reino de Valencia. En 1404 se aplicab tres asientos sobre las agallas que iban desde El Grau hasta Túnez, Orán y Berbería (Contreras Zamorano, 2015, p. 335). Y en el año 1439, se documenta dos transacciones destacables, los 203 cantaria que los venecianos envían de Candía a Mallorca (Dorini y Bertelè, 1956, p. 524 y Durán i Duelt, 2008, p. 247) y las agallas que llevan a Mediona desde Mallorca y Quíos (Salicrú i Lluch, 1995, p. 169), lugar importante éste último, porque otras naves, como la de Cosme Dentuto, partieron desde allí para abastecer con 19 sacos de agallas a Flandes e Inglaterra (Durán i Duelt, 2008, p. 247).

Respecto a la Corona de Castilla, la documentación es menos generosa sobre este producto, a pesar de la evidencia de su consumo. De hecho, la toponimia demuestra tal afirmación pues durante la repoblación de Fernando II y la implantación de la diócesis de Ciudad Rodrigo en la segunda mitad del siglo XII, surgió la villa denominada "De las Agallas" manteniendo su préstamo y beneficio eclesiástico en 1454 y conservando el topónimo en la actualidad (Hernández Vegas, 1935, vol. 1, pp. 225-226). En el caso de la ciudad de Córdoba para 1492, cuando se realiza la declaración del arancel del almojarifazgo de la villa de Chillón perteneciente a don Diego Fernández de Córdoba, alcaide de los Donceles, se nombra "pastel y otros tyntes" como "agave e resuras e agallas e pastel e ruvia e fustete e otras quales quier que tyntare que se trajeren a vender a la dicha villa que pague de lo que vendieren la veyntena"16. Finalmente será el Reino de Granada quien proporcione dos ejemplos del comercio de las agallas, uno antes de su conquista en 1452, que muestra la exportación de 79 sacos de agallas de Génova a Granada (Airaldi, 1966, pp. 26-61); y otro de 1501, cuando se produce la venta de la arroba de agallas por 2 maravedíes (Trillo San José, 1996, p. 255 y p. 269).

16 1492.06.20, Archivo General de Simancas (en adelante AGS), Registro General del Sello (en adelante RGS), 18, fol. 5 r. 
A pesar de su sustitución por otras materias primas o su prohibición en el ámbito textil en varias zonas de España al considerarse un mordiente de peor calidad, su mínima comercialización manifiesta que todavía tenía una cierta función en los siglos bajomedievales. Las utilidades que se le otorgaron muestran una menor pero continua presencia en las diversas industrias y su consumo por la sociedad de aquellos momentos. En el Manuscrito de Bolonia se ofrece indicaciones para conocer las buenas agallas antes de recogerlas. Según parece, las de calidad debían ser pequeñas, rugosas, firmes por dentro y polvorientas por fuera (Merrifield, 1967, vol. II, pp. 595-596, cap. 389). En las recetas consultadas, el método más sencillo de obtener el mayor provecho del tanino es rompiendo las agallas en pequeños trozos, triturarlas y/o dejarlas en forma de polvo (Fig. 2). Después, en función del empleo al que se le destine, cada procedimiento artesanal requiere que se dejen macerando un tiempo en agua, aceite de oliva o vino. A continuación, y en la mayoría de los casos, se indica que se disuelva en cualquiera de dichos líquidos en un recipiente y se hierva o se deje secándose al sol, para su mezcla posterior con otras sustancias.

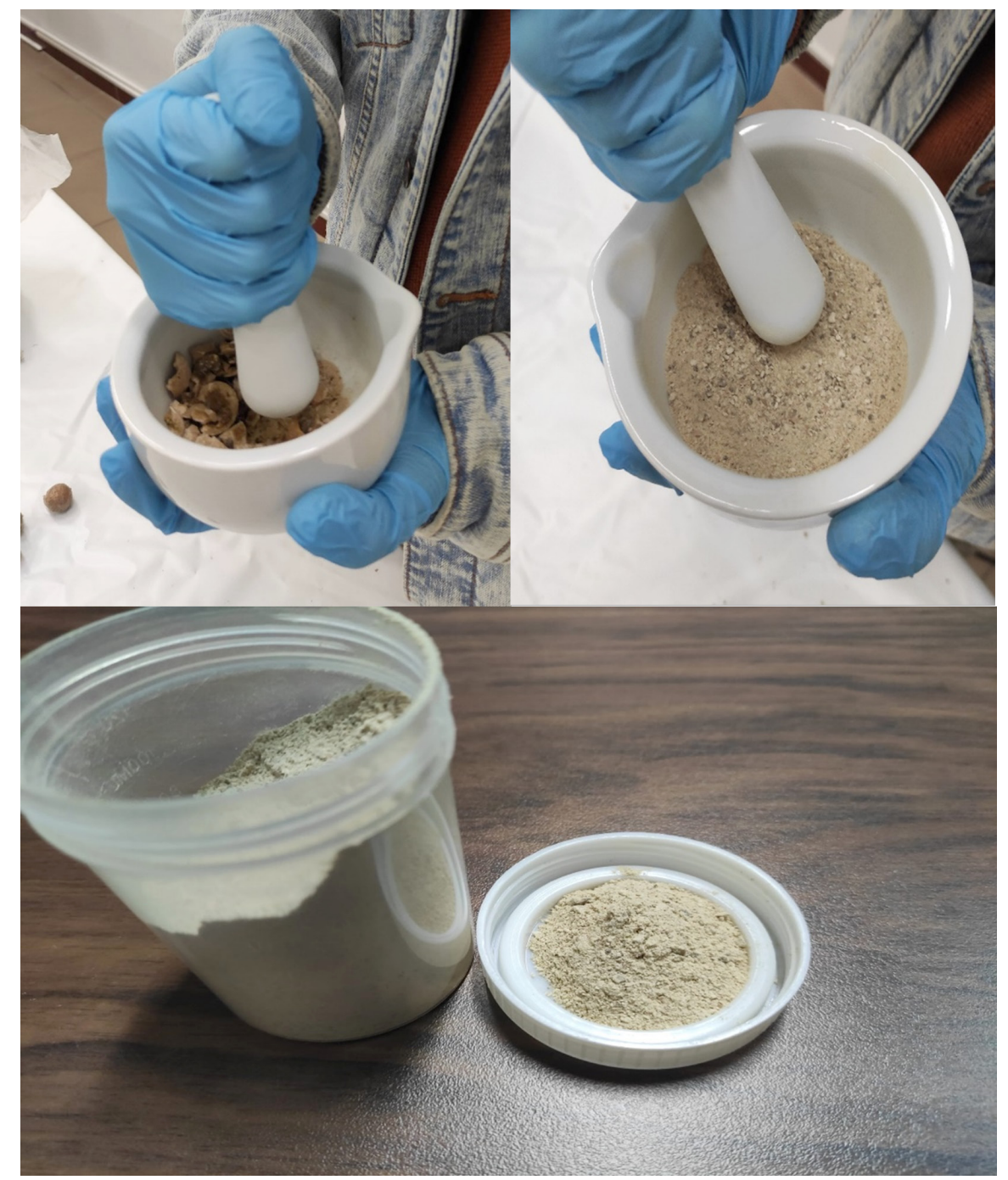

Fig. 2. Proceso de transformación de las agallas en polvo. (Fotografías propias del autor). 


\subsection{Componente de tintas metaloácidas}

Una de las principales y más conocidas utilidades de la nuez de agalla, ha sido aportar la tonalidad negra a las tintas de escritura ferrogálicas, gracias a sus ácidos tánico y gálico producen una reacción química al mezclarse con sulfato de hierro (vitriolo verde o caparrosa) o sulfato de cobre (vitriolo azul). Las primeras noticias del uso de las agallas para hacer tinta negra para escribir se localizan en la obra de Filón de Bizancio en el siglo II. d. C, para elaborar "tinta simpática", pero la receta más completa y antigua proviene del Papiro Griego V de Leiden (ss. III-IV) (Zerdoun BatYehouda, 1983, p. 91). En Europa Occidental, la obra de Marciano Capella del siglo V y después San Isidoro de Sevilla en sus Etimologías, aluden al uso de la agalla para la fabricación de tinta (Kroustallis, 2008, p. 153). En realidad, a partir del siglo XII será cuando las tintas metaloácidas comiencen a sustituir a las carbónicas. En este sentido, destaca una de las recetas localizadas en el Schedula Diversarum Artium de Teófilo, fechado en el siglo XII (De Hamel, 2001, pp. 32-33). Desde el siglo XIII las tintas ferrogálicas están implantadas y varios recetarios europeos así lo demuestran, por ejemplo, en la gran diversidad recogida por M. Zerdoun de diferentes regiones (Zerdoun Bat-Yehouda, 1983, pp. 249-282), las recetas procedentes del Fondo Palatino de la Biblioteca Nacional de Florencia de los siglos XIV-XVI (Pomaro, 1991, pp. 109-114, Pal. 796, Pal. 857, Pal. 885, Pal. 915 y Pal. 941) o las incluidas en los Manuscritos de Jehan Le Begue de 1431 de Experimenta de coloribus (Merrifield, 1967, vol. I, p. 68, p. 84, pp. 288-291) y Manuscrito de Padua del siglo XVI (Merrifield, 1967, vol. II, pp. 676-677).

En el caso de España, además de la referencia de San Isidoro de Sevilla sobre las agallas para hacer tinta en sus Etimologías, la primera receta donde se deja constancia de la mezcla de agallas, vitriolo, goma y agua para elaborar tinta de color negro, se encuentra en Ramón Llul (1232-1315) en el capítulo 291, 21 de su Llibre de la Contemplació en Deu (Kroustallis, 2002, p. 101). Muy similar a esta receta, es la perteneciente al notario valenciano Andreu Julià al emplear agallas, vitriolo o acije, goma, vino y alumbre (Cárcel Ortí y Trenchs Odena, 1979, p. 424). Desde el siglo XIII en la Península Ibérica se refleja muy bien la forma de manipular las agallas para que sean óptimas de cara a la elaboración de este tipo de tinta de escritura. En la mayoría de las recetas consultadas, coinciden en la necesidad de romper las agallas o hacer polvos de ellas antes de emplearlas en cualquier procedimiento. En una receta procedente de un Protocolo Notarial del Archivo Histórico Provincial de Córdoba de 1474, se refleja que, para hacer tinta negra, hay que utilizar agallas "bien quebradas" (Córdoba de la Llave, 2005, p. 32) ${ }^{17}$. Las recetas del siglo XV sobre tinta negra procedentes del Libro de los Oficios del Monasterio de Nuestra Señora de

17 1474.s.d., Archivo Histórico Provincial de Córdoba (en adelante AHPCO), Protocolo Notarial de Córdoba (en adelante PNCO), 14121P, 5, fol. 58v. 
Guadalupe también señalan "echar en una escudilla las agallas bien partidas", "toma tres libras de agallas, molidas y partidas" o "toma tres libras de agallas bien molidas" (Cabanes, 2007, pp. 368-370) ${ }^{18}$. En el Ms. 9226 se recogen hasta seis recetas para fabricar tinta negra, en todas ellas se especifica la necesidad de tener agallas partidas, quebradas o finas ${ }^{19}$, y lo mismo sucede para el manuscrito castellano H-490 que explicita el "romper las agallas" en una receta de tinta (Córdoba de la Llave, 2005, p. 46). Incluso en una receta del año 1500, también alude a cuatro onzas de agallas "buenas finas menudas y moledlas muy bien molidas"20. Aunque era más habitual en cosmética, como se plasmará más adelante, también para la tinta de escribir la agalla se convertía en polvo para favorecer su disolución posteriormente en líquidos como vino o agua. Por ejemplo, el recetario de Alejo Piamontés del siglo XVI asegura que para mejorar la tinta "echad de los dichos polvos de carbón de caparrosa, de agallas y goma y esta será también buena" ${ }^{21}$. Una similitud que se encuentra en recetas procedentes del Fondo Palatino de la Biblioteca Central de Florencia al citar la agalla en polvo para su tratamiento ${ }^{22}$.

Una vez preparada la agalla, fragmentada en pequeños trozos o en polvo, se lleva a cabo el proceso que permite extraer el tanino, ya sea por maceración o por cocción. Respecto a la primera alternativa, lo habitual era sumergirla en un disolvente como vino o agua y permanecer varios días en remojo. Dependiendo de la receta, se le añaden todas las sustancias de una vez o se van incorporando en determinados momentos. Los resultados del estudio de Criado Vega apuntan que la maceración solía obtener mayor porcentaje de ácido tánico y en menor tiempo, si se empleaba el vino (Criado Vega, 2013, pp. 338-340). En recetarios hispanos aparecen varios ejemplos del uso de la maceración en agua o vino, como en las diversas recetas del Ms. 9226 que detallan "echa a remojar en açumbre y medio de agua o vino seis onças de agallas partidas y déjalas cuatro o çinco días..." ${ }^{23}$ o "en una olla zamorana, a una

18 Regla para hazer tynta, fols. 201r-v.; Recebta para hazer tinta sin fuego para el papel delgado o pergamino delgado, fols. 202r-203r. y Recepta para hazer tinta sin fuego para letra y punto grueso en pergamino, fols. $202 \mathrm{v}-203 \mathrm{v}$.

19 Siglos XV-XVI, Biblioteca Nacional de España (en adelante BNE), Ms. 9226, Reçepta para tinta negra para papel y para pergamino, fol. 35r, Tinta negra, fol. 71r, dos recetas más en fol. 73r., dos recetas en fol. $73 \mathrm{v}$. y Tinta negra, fol. 106r. y fol. 112r.

20 1500.01.01, AGS, Cámara de Castilla (en adelante CCA), Cédulas (en adelante CED), 8, 125, 3, doc. 372, Receta de tinta.

21 1563, libro V, fols. 162v-163r. Libro de los secretos del Reverendo don Alexo Piamontés. De nuevo por el mesmo autor corregido e emendado con adición de muchas cosas notables. Traducido de lengua italiana en española. Impreso en Çaragoça en casa de la viuda de Bartholomé de Nágera. Año MDLXIII, véndese en casa de Antonio de Furno, mercader de libros de Çaragoça.

22 Siglo XVI, Pal. 796, fol. 49v., i [n] ciostro fine y siglo XV, Pal. 857, fol. 115r., Polvere da fare inchiostro. Pomaro, 1991, pp. 109-110.

23 Siglos XV-XVI, BNE, Ms. 9226, Reçepta para tinta negra para papel y para pergamino, fol. 35r. y similar en Tinta negra, fol. 73r. 
açumbre de vino, echa cuatro onças de agallas..." ${ }^{24}$. De igual manera se aprecia en la receta del Ms. H-490 señalando que permanezcan "en remojo en tres cuartillos de agua durante tres días" (Córdoba de la Llave, 2005, p. 46). En contrapartida, existen referencias sobre su cocción, o bien al sol mientras están en reposo o a través de su calentamiento al fuego en algún recipiente. Por ejemplo, en la receta de 1500 se explica que después de preparar todos los ingredientes, "cozer el vino e las agallas fasta que mengue la terçia parte y después quitarlo del fuego e colar" 25 mientras que el Ms. II/1393(6) aparece que esté ocho días al sol'26. La receta de Guadalupe para hacer tinta opta por el uso del fuego mezclando las agallas con agua o vino blanco mientras que las otras dedicadas a fabricar la tinta sin fuego, las dejan cinco o seis días macerando ${ }^{27}$. Otras dos recetas prefieren el fuego, la de 1474 de Córdoba al explicar que "después coseldas sobre fuego de carbón muy manso quanto escomiençe a feruir", y el Ms. H-490 que apuesta por cocer la mezcla hasta que se reduzca tres partes de agua y, en caso de hervir, que se cuele (Córdoba de la Llave, 2005, p. 46). El Ms. II/1393(6) en la receta para hacer dos aguas para escribir, recomienda que las agallas sean molidas y destempladas en agua ${ }^{28}$.

En gran medida, los recetarios europeos mantienen los mismos procedimientos. Para el caso italiano, Alejo Piamontés recomienda las dos posibilidades, "ponerlas en una sartén de fierro con un poco de açeyte y freidlas..." o "remojar tres onzas de agallas arrugadas y espesas, rotas en pedaçitos y déjalas dos días al sol" 29 . En las recetas del Fondo Palatino de Florencia, igualmente se dejan en remojo y reposar varios días con los ingredientes troceados sin recurrir al fuego ${ }^{30}$, dejar la mezcla al sol ${ }^{31} \mathrm{o}$ directamente hervirla para su cocción como mínimo una hora de duración ${ }^{32}$. La receta Inchiostro finissimo come si faccia del Manuscrito de Padua del siglo XVI, aconseja que las agallas de Istria, una vez rotas y sumergidas en vino blanco, deben dejarse al sol o removiendo en una olla tapada (Merrifield, 1967, vol. II, pp. 676-677, cap.

24 Siglos XV-XVI, BNE, Ms. 9226, Tinta negra, fol. 71r.; Otra de fray Alfonso de Palencia, fol. 71r., Otra del mesmo fol. 71r.; Otra tinta del mesmo, fol. 72r. y Tinta negra, fol. 112r.,

25 1500.01.01, AGS, CCA, CED, 8, 125, 3, doc. 372, Receta de tinta.

26 Siglo XVI, Biblioteca del Palacio Real (en adelante BPR), Ms. II/1393(6), Receutas en nombre del Doctor Segura, publicados para toda quantas cosas ay en el mundo de sutilezas, como son tinta, para perfumes, para prebas, fol. 73r. Receta Tinta. Criado Vega, 2013, p. 12.

27 Regla para hazer tynta, fols. 201r-v.; Recebta para hazer tinta sin fuego para el papel delgado o pergamino delgado, fols. 202r-203r. y Recepta para hazer tinta sin fuego para letra y punto grueso en pergamino, fols. 202v-203v.

28 Siglo XVI, BPR, Ms. II/1393(6), fol.76r. Receta Para dos aguas que scriviendo como la vna en blanco y mojando lo escrito con la otra se tornan las letras negras.

29 1563, libro V, fols. 161r-161v. y libro IV, fol. 41r., Libro de los secretos del Reverendo don Alexo Piamontés.

30 Siglo XVI, Pal. 796, fol. 49r., a fare inciostro buono; fol. 49v., di fare inciostro crudo. Pomaro, 1991, pp. 109-110.

31 Siglo XVI, Pal. 941, fol. 32r., a fare inchiostro fine optimo. Pomaro, 1991, p. 112.

32 Siglo XVI, Pal. 796, fols. 49v.-50r., i [n] ciostro fine; Siglo XIV, Pal. 885, fol. 259v., inchiostro fine y Siglo XVI, Pal. 915, fol. 9v., inchiostro del Rossellí. Pomaro, 1991, pp. 110-111. 
61). En el fondo de los códices Borgiani Latini de la Biblioteca Apostólica Vaticana, aparece una receta del siglo XV denominada Modo di fare inchiostro perfetissimo, donde se plasma el uso de vitriolo romano, vino blanco y dos onzas de agallas ${ }^{33}$. En Experimenta Coloribus de los Manuscritos de Jehan Le Begue de 1431 se refleja ambas soluciones, trocear las agallas y hacer su disolución en vino macerando durante doce días y emplear el fuego con agua y echar las agallas (Merrifield, 1967, vol. I, p. 68, cap. 47 y p. 84, cap. 89). Otros paralelos sobre decocción y maceración se pueden encontrar en el estudio de M. Zerdoun (Zerdoun Bat-Yehouda, 1983, pp. 249-282). De manera definitiva, una vez realizados todos los pasos anteriores, se cuela y se guarda la tinta obtenida en cualquier recipiente para su posterior utilización.

Aunque queda claro que la agalla tiene un papel principal en este tipo de tintas de escritura, existen en menor medida, otras recetas que confirman que esta materia vegetal fue importante para volver a recuperar las letras que se han ido gastando con el paso del tiempo o con el fin de elaborar otras tintas. Así lo revela una receta del Ms. 9226 y de Alejo Piamontés, que bajo el título Para renovar las letras gastadas y viejas y Para renovar las letras antiguas ya gastadas, explican que se piquen las agallas, se dejen en remojo en vino blanco durante un día para después destilarlas y emplearlas en el soporte escrito ${ }^{34}$. En cuanto a otras tintas, Alejo Piamontés menciona que, con el agua destilada de agallas verdes, cardenillo y vinagre fuerte, se consigue tinta verde ${ }^{35}$. Parecido se recoge en las recetas de G. Pomaro bajo títulos como a ffare lettare verdi o a ffare tentura verde da escrivere, usando agua de agallas verdes ${ }^{36}$.

\subsection{Mordiente y tinte en el sector textil}

Otra de las funciones más conocidas de la nuez de agalla es su aplicación como curtiente en pieles y mordiente y tinte de los tejidos. La mayoría de las referencias se centran en su actuación como fijador de colores y para aplicar la tonalidad negra. Para el teñido de sedas y pieles, fue un ingrediente principal, documentado en Al-Andalus desde fines del siglo IX y principios del X (Saladrigas, 1996, p. 87). En los siglos medievales el alumbre se convertirá en el principal mordiente, aunque a veces fue sustituido por el tártaro y la agalla (Iradiel Murugarren, 1974, pp. 176-179 y Córdoba de la Llave, 2012, vol. 2, pp. 1189-1200). La aplicación del mordiente se produce sobre la piel antes del tinte, así ayuda que el colorante se fije con mayor rotundidad y avive el color. En el caso de la agalla, gracias a su ácido gálico permite esa consolidación del tinte con una tonalidad más intensa (Cifuentes i Comamala

33 Siglo XV, Biblioteca Apostólica Vaticana, Borg. Lat. 416.

34 Siglos XV-XVI, BNE, Ms. 9226, fol. 19r. y 1563, libro II, fol. 15r., Libro de los secretos del Reverendo don Alexo Piamontés.

35 1563, libro II, fol. 15r., Libro de los secretos del Reverendo don Alexo Piamontés.

36 Siglos XV-XVI, Pal. 796, fol. 5r. y fol. 6v. Pomaro, 1991, pp. 113-114. 
y Córdoba de la Llave, 2011, p. 75). En el manual del tintorero de Joanot Valero del siglo $\mathrm{XV}$, la agalla actúa como fijador junto al tártaro en la receta 8 para paños ingleses, con alumbre y tártaro en paños bureles como la receta 9 y para conseguir negros sin azul en la 23 (Cifuentes i Comamala y Córdoba de la Llave, 2011, pp. 98, 161,163 y 175). Sin embargo, con el alumbrado de las sedas es cuando se nombra la agalla continuamente y de ahí el origen de la expresión "engallar" la seda. En el ámbito hispano, se encuentran ejemplos de ello, en el Ms. 2019 existe una receta para teñir la seda de color pardo o negro, explicando que debe ser hervida en agua y enfriada para después bañar las madejas de seda (Criado Vega, 2013, p. 128). En el caso de Córdoba, las ordenanzas de 1529 mezclan agua, diez onzas de agallas, dos de caparrosa y dos de goma arábiga. Se debía llevar a cabo ocho baños de la seda y otro final con vinagre (Córdoba de la Llave, 1990, p. 108). Uno de los ejemplos más interesantes, data del siglo XIII. Se trata de la capa del infante don Felipe, localizada en el Museo Arqueológico Nacional y sometida a una serie de análisis químicos para conocer los colorantes. Los resultados manifestaron que está conformada por hilos azules teñidos de agalla y añil, anaranjados, rojos y granates teñidos con agalla y grana y amarillos con agalla y zumaque o azafrán (Córdoba de la Llave, 2002, p. 351 y De los Santos Rodríguez y Suárez Smith, 1997, p. 239).

Semejante a lo explicado para la fabricación de la tinta de escribir, para obtener el tinte negro, se empleaba la nuez de agalla y el sulfato de hierro (vitriolo o caparrosa) (Córdoba de la Llave, 2005, p. 12). De nuevo en el manuscrito de Joanot Valero se localizan diversas recetas dedicadas al tinte, donde la agalla se incluye como un ingrediente más, en paños morados (recetas 21 y 31), negros (13, 22, 24 y 36), bermejos ( 28 y 138) y escarlatines (29) (Cifuentes i Comamala y Córdoba de la Llave, 2011, pp. 75, 167, 173, 175, 179, 181 183, 185, 237). Por su parte, el manuscrito H-490 de la Biblioteca de la Facultad de Medicina de Montpellier también confirma su uso como colorante para teñir las pieles en negro. Una vez más, se alude a las agallas molidas y su mezcla con acije para el tono deseado (Córdoba de la Llave, 2005, p. 40, cap. 1). En las ordenanzas de Sevilla y Córdoba, aparecen referencias sobre las agallas para el teñido. Para el caso hispalense, en la ordenanza de los sederos, se deja claro que "el sirgo prieto que lo faga sobre agalla como para terciopelo o con carca; y que no le eche azeyte ni çumaque ni otras cosas que le echa para cargar..." 37 . El concejo cordobés dispuso de diferentes normativas para controlar el teñido de diferentes paños y mordientes. En una gran parte de ellas, se cita las agallas como sustancia para morados ${ }^{38}$. A pesar de que, como ya se ha indicado, la

37 1527, Recopilación de las ordenanzas de la muy noble e muy leal çibdad de Sevilla, fol. 189v.

38 González Jiménez et al., 2016, p. 224, [16] Los morados, para color negro prohibiendo, a veces, el empleo del zumaque y apostando por el uso único de la agalla, González Jiménez et al., 2016, p. 222, [7] Que se den a los paños negros XXXV libras de rubia, p. 223, [11] Los lutos, p. 227, [30] Frisas pardillas, p. 244, [1] Frisas de luto, y otras disposiciones sobre el teñido y mordiente con agallas, González Jiménez et al., 
agalla comenzó a limitarse y prohibirse en algunas zonas de España al considerarse de peor calidad que cualquier otro mordiente, como en Murcia, Cuenca o Valencia (Iradiel Murugarren, 1974, pp. 176-179 y García Marsilla, 2017, p. 299); en otras ciudades no fue así, como evidencia las normativas de los concejos de Sevilla o Córdoba (Córdoba de la Llave, 1990, p. 70).

En el marco europeo, similar al caso de España, en los siglos medievales la agalla también formaba parte del proceso de fijación de los colorantes y para obtener tintes. Por ejemplo, en el Mappa Clavícula se mencionan algunas recetas donde se sirve de la agalla para hacer azul celeste y teñir de morado las pieles (Smith y Hawthorne, 1974, p. 56 y p. 63). Claramente donde se tiene mayor constancia del protagonismo de la nuez de agalla es en la industria textil italiana. El Manuscrito de Bolonia, describe su uso como mordiente y para color negro (Merrifield, 1967, vol. II, p. 547 y p. 600, por ejemplo, caps. 326, 327, 339 y 340), mientras que el manual Plictho dell'arte dei tintori de G. Rossetti está compuesto por doce recetas que obtienen el color negro como resultado de la utilización de sales de hierro y taninos de agalla y zumaque. En concreto, una de las recetas expone el empleo de agalla, hierro oxidado y vinagre; y otra una combinación de agalla molida, vitriolo y limadura de hierro con aceite de linaza y lejía (Córdoba de la Llave, 2005, p. 13; Edelstein y Borghetty, 1969, p. 4 y p. 10 (facsímil)). Los manuscritos 796, 916 y 941 de Florencia proporcionan recetas similares. El primero, para hacer bermellón recomienda sumergir la seda o hilo en agua caliente de agalla y para teñir de negro un pergamino, una onza de agalla, una de vitriolo y una de goma arábiga ${ }^{39}$. En cuanto al segundo, para tener color negro se determina agalla, vitriolo y goma arábiga y un posterior untado con aceite (Córdoba de la Llave, 2005, p. 14), mientras que el tercero, recurre a agalla, agua, vitriolo y goma arábiga ${ }^{40}$. El Ms. Antinori 14 del siglo XIV, de la Biblioteca Laurenziana mezcla agalla y vitriolo disuelta en agua de escotano (Córdoba de la Llave, 2005, p. 14). Por su parte, G. Rebora identificó hasta catorce recetas en el manual del tintorero del siglo XV que estudió, donde la "galla" o "gala" está muy presente para alcanzar los colores negros (Rebora, 1970, pp. 61-64, 68, 73-74, 82, 89, 102, 112, 114-115 y 127). Y Alejo Piamontés tanto para teñir cordobanes verdes como para el carmesí incluye las agallas molidas como fijador ${ }^{41}$, sin olvidar las cincuenta recetas de tintura de lana pertenecientes a un libro anónimo de 1513 denominado Libro de las maravillas, donde se menciona la agalla como colorante para el negro, entre otros colores y materias primas (Cifuentes i Comamala y Córdoba de la Llave, 2011, p. 32).

2016, p. 226, [24] Echar rubia e non sangre, pp. 226-227, [26] Echa dos açumbres de tynta, p. 228, [33] Como se han de fazer los bureles a fuer de Valencia, p. 235, [54] De los paños bureles fechos syn tinta, p. 240,

[1] Bureles, [2] Los sezenes para lutos, [4] Los bureles y p. 302, las disposiciones 9 y 11 de Hordenança de las tintas e del fazer de los bureles.

39 Siglos XV-XVI, Pal. 796, fol. 7r. y fol. 14r. Pomaro, 1991, pp. 114-145.

40 Siglo XVI, Pal. 941, fol. 32r. Pomaro, 1991, p. 147.

41 1563, libro V, fol. 147r. y fols. 151v.-152r., Libro de los secretos del Reverendo don Alexo Piamontés. 


\subsection{Sustancia médica y curativa}

Hasta el momento ha quedado manifiesta la importancia que ha tenido la nuez de agalla para la fabricación de tinta de escribir y en el ámbito textil. Sin embargo, además de las anteriores, este recurso natural se ha destinado a otros fines menos conocidos y que igualmente fueron trascendentales como, por ejemplo, la farmacología y la medicina. Desde época grecorromana autores como Hipócrates, Plinio, Teofrasto o Dioscórides, entre otros, hicieron referencia al tratamiento de ciertas afecciones que los taninos podían ayudar a su atenuación. Según parece, en Egipto las empleaban como astringentes intestinales y en los tratados medicinales de la Antigüedad clásica, al menos así lo transmite Celso, estas materias vegetales eran idóneas como desinfectantes, cauterizantes, hemostáticos y formando parte de remedios para dolores bucales, purgar el cerebro, drenar granos y paliar dolores de personas jóvenes (Kroustallis, 2003, p. 580). De hecho, en la conocida ciudad de Herculano, sepultada por la erupción del Vesubio en el 79 d. C., aparecieron restos de agallas vegetales de Andricus Killari para venta medicinal (Nieves-Aldrey, 1998, p. 3). El mismo Hipócrates en el siglo IV a. C., nombra las agallas para tratar las úlceras y las hemorragias, mezclándolas con un compuesto a base de mirra, incienso, herrumbre, flor de cobre, cocido después en vino (Hipócrates, ed. de 1993, p. 295). Cuando el médico griego Dioscórides alude a este recurso natural, concreta que:

"son bastante astringentes. Majadas, constriñen las carnes superfluas, los humores de las encías y de la campanilla, y las aftas de la boca. El corazoncillo de ambas, metido en la caries de los dientes, calma los dolores. Quemadas sobre la brasa, hasta la inflamación, y matadas con vino, o con vinagre, o con salmuera aceda, son remedio hemostático. Su decocción es eficaz, en baños de asiento, contra los prolapsos y los humores de matriz... Majadas, aplicadas con agua o con vino, y bebidas, son convenientes contra los flujos disentéricos y celíacos; también lo son mezcladas en la comida, o hervidas enteras previamente en el agua, en la que va a cocerse alguna cosa de las adecuadas contra las mismas afecciones" (Dioscórides, ed. de 1998, Libro I, p. 209).

También el médico romano Celso, en su obra De medicina ${ }^{42}$, recomienda que la tinta negra de escribir se emplee como desinfectante tras el afeitado de la cabeza en el tratamiento contra la alopecia, y su uso en heridas que puedan conllevar la rotura del cráneo (Kroustallis, 2003, p. 581).

En el período medieval, se mantuvo la utilización de las agallas en materia médica teniendo una referencia clara en la Etimologías de San Isidoro de Sevilla (San Isidoro, ed. de 2004, libro XVII, p. 1181). S. Kroustallis destaca una receta del siglo XI del Archivo Capitular de Ivrea, donde hay un medicamento para tratar la pérdida de la vista usándose tinta negra con taninos (Kroustallis, 2003, p. 581). En el mun-

42 Siglo XV, Biblioteca Apostólica Vaticana, Vat. Lat. 4424, fols. 1r-80v. 
do árabe también se administraba como astringente y reductor de fiebre (Zerdoun Bat-Yehouda, 1983, pp. 342-343). Sobre el estudio del vocablo árabe de la palabra agalla, se afirma que en árabe magrebí tiene un significado de "astringente o acerbo, nombre que se le dio por su sabor a la agalla" y los musulmanes utilizaban "píldoras de agalla". Para el siglo XIV, el propio Ibn al-Jatib expone que para el tratamiento de los ojos es eficaz "cenizas de madera de vid y colirio seco de celidonio de flores rojas, goma arábiga y agalla, una porción de cada uno" (Maíllo Salgado, 1998, p. 255). A partir del siglo XII comenzó a llegar a Europa una profusa transmisión del saber técnico, tanto por la traducción de textos griegos al árabe como por los propios tratados musulmanes, destacando el Tacuinum Sanitatis de Ibn Butlán del siglo XI o el Secretum secretorum de Maimónides, entre otros. Posteriormente comenzarán a surgir numerosas obras de medicina como las de Pedro Hispano (1210-1277), Arnau de Vilanova (1234-1311) o Alonso de Chirino (1365-1429) y muchos más especialistas que incluyen la agalla en sus procedimientos (Martínez Crespo, 1995, p. 12). Algunos boticarios también solían tener esta materia prima entre sus ingredientes, como Guillem Ros que posee dos inventarios del siglo XIV en el que señala "quatuor uncias gale ad tres denarios", "octo libras gale piccate sutil ad quatuor solidos" y "unam libram gale modici valoris ad quatuor denarios" (Alomar i Canyelles, 2002, pp. 90, 95 y 98).

En términos generales y a tenor de los recetarios consultados, en la Península Ibérica la agalla estaba muy relacionada con las enfermedades y complicaciones bucales, una función que Dioscórides ya indicó en su tiempo al especificar que "molidas resuelven la carne superflua, reprimen los humores que destilan a las enzías y también a la campanilla, y sueldan aquellas llagas que en la boca suelen sobrevenir a los niños (Dioscórides, ed. de 1998, Libro I, p. 94). En su obra Practica redactada a mediados del siglo XII, Plateario, autor de la Escuela Médica de Salerno, menciona la agalla para combatir los dolores dentales, mezclada con otros ingredientes (Recio Muñoz, 2016, p. 399). El Ms. 834 o Manual de mugeres recoge un remedio para el neguijón (enfermedad de los dientes que los desgasta y vuelve negros) con jengibre, nuez moscada, clavos, corazón de pino, romero, alumbre, salvia, lentisco y agallas. Todo ello se cuece en vino, se cuela y se debía enjuagar la boca ${ }^{43}$. Similar es la receta recogida en el recetario del médico navarro Juan Vallés (1496-1563) para "refirmar los dientes y apretar las enzías floxas y hinchadas y hazerlas crecer". En esta ocasión se reúnen numerosos ingredientes, encontrándose las agallas de roble, que debían ir molidas con el resto de los componentes, cocerse en vino, agua rosada y agua y colarse el producto final para utilizarlo en forma de enjuague bucal. También proporciona la opción de hacer de estos polvos una mezcla con miel rosada y vinagre y transformarlo en una especie de ungüento (Serrano Larráyoz, 2008, pp.

43 Siglo XVI, Biblioteca Palatina de Parma (en adelante BPP), Ms. 834, Manual de mugeres Manual de Mugeres en el qual se contienen muchas y diversas reçeutas muy buenas, fols.7r-7v. Martínez Crespo, 1995, p. 49. 
317-318 $)^{44}$. En este Ms. 11160 se halla otra receta dedicada a curar las llagas con un "azeyte stíptico". Entre la multitud de elementos que compone la fórmula, se nombra las agallas de Levante junto a otras materias de origen vegetal como nueces de ciprés, cáscaras de granadas, cabos tiernos de ramos de olivo o arrayán, entre otros. El procedimiento es más complejo, pues hay que dejarlo todo troceado en vinagre durante cuatro días, cocerlo al fuego, colarlo, destilarlo con otras sustancias adicionales como miel rosada y guardarse en una redoma para su futura aplicación (Serrano Larráyoz, 2008, pp. 427-428).

Además de sus propiedades para curar y prevenir las dolencias bucales, la nuez de agalla también era útil para las hemorragias. La obra del médico Abü-1- 'Ala' Zuhr (1060-1131), padre de Avenzoar, estudiada por $\mathrm{M}^{a} \mathrm{~L}$. Arvide, contiene una cura para la perforación y sangre del oído en la que se incluye la agalla. Menciona las hojas de hiedra y la agalla, se cuecen en vinagre y se instila dentro del oído para cortar la hemorragia, aunque también puede hacerse con vinagre y ungüento de rosa (Arvide Cambra, 1993, p. 326). De nuevo Plateario, para mediados del siglo XII, menciona el uso de la agalla para contener la hemorragia menstrual (Recio Muñoz, 2016, p. 53 y p. 743). En el siglo XV, el Ms. denominado códice Zabálburu, contiene tres recetas destinadas a este fin. Una para el que salle sangre a menudo por las narizes, explicando como en casos anteriores, que se hierva en vino cascos de milgranas (granadas) y media onza de agallas (Pensado Figueiras, 2012, p. 166, núm. 12). La segunda, denominada para el que salle sangre de las narizes dispone que hay que lavar la cabeza con agua fría y por la nariz introducir polvos de agallas quemados, en caso de no funcionar, facilita otro procedimiento con nueces llenas de pez (Pensado Figueiras, 2012, p. 167, núm. 22). La última receta es destinada para las personas que escupen sangre, la medicina que se elabora contiene media onza de agallas que iría mezclada con otras sustancias. El resultado final sería un líquido que debía beber la persona enferma (Pensado Figueiras, 2012, pp. 168-169, núm. 29). Con el mismo enfoque está destinado un recetario morisco de carácter médico y veterinario, datado entre los siglos XV y XVI bajo el título de Libro que contiene temas concernientes a veterinaria y asuntos semejantes que revisten gran utilidad. Entre los remedios que aporta, existe uno dedicado a la cura y cicatrización de heridas y posibles hemorragias. Los ingredientes para cicatrizar son aceite de oliva, agalla, almáciga, incienso, sangre de dragón, tierra de Sevilla y vinagre; mientras que para la hemorragia además del aceite de oliva, la agalla, almástiga y vinagre, se le añade estoraque (Vázquez de Benito y Bustos, 1997-1998, p. 389). Los pasos para detener una hemorragia serían:

"113. Sobre cómo detener la hemorragia de sangre en las heridas.

Pon sobre la herida un paño de lino empapado en agua fría que dejarás hasta que la sangre deje de manar. Si con esto no fuere suficiente, espolvorea sobre la herida

44 Agradezco a Fernando Serrano su gentileza de proporcionarme la obra y facsímil en versión digital. 
tierra de Sevilla molida con aceite de oliva y agalla, después venda con un paño durante dos o tres días, porque la sangre cesará de manar. ¡Permítalo Dios!” (Vázquez de Benito y Bustos, 1997-1998, p. 456).

En último lugar, la agalla se ha incluido igualmente en recetas para otros males y dolencias. De nuevo en el códice Zabálburu es posible localizar una receta para la enfermedat de la piedra en la que "non puede omne mear e será en gran apretamiento e echara arena" (Pensado Figueiras, 2012, p. 170). Todo lo empleado consiste en sustancias vegetales y naturales, incluidas las agallas. El modo de hacerlo es el plasmado por recetas anteriores, se tritura todo, se amasa con miel y cada mañana el paciente debe ingerirlo. En el Ms. 9226 hay una medicina para el mal de cámaras y que además de ingredientes muy peculiares, como pelos de liebre o lana sucia, se encuentra la agalla de ciprés. El resultado de la receta es que se elabore una especie de mermelada que debe ser consumida por el paciente diariamente ${ }^{45}$.

En la Europa medieval hay muestras de la misma manipulación de la agalla para aprovechar sus propiedades medicinales. Del siglo XIV data el Ms. Reg. Lat. 1211 con dos recetas de tinta negra para medicina, procedente de la Biblioteca Apostólica Vaticana para sanar heridas y cortar las hemorragias de la nariz, así como un ungüento para cicatrizar heridas (Kroustallis, 2003, pp. 581-582). En el Libro de secretos de Alejo Piamontés, se referencia que el incienso molido con linardo y agallas, mezclado con vino caliente es bueno para el flujo de cámaras ${ }^{46}$. Incluso en un tratado hebreo, cuyo contenido procede mayoritariamente del famoso Trotula, como remedio para detener la sangre recomienda purgar el brazo o la mano y posteriormente aplicar el agua donde se haya hervido algún astringente como las agallas, entre otras sustancias. De igual forma, para tratar las llagas de la matriz aconsejan una lavativa con diversos ingredientes, incluyéndose nuevamente las agallas vegetales (Caballero Navas, 2006, pp. 401 y 408).

\subsection{Elemento cosmético}

Mujeres y hombres de la sociedad medieval se preocupaban por su aspecto físico, sentirse bellos y bien consigo mismo y manifestarlo ante el resto de las capas sociales no era tan extraño como se puede creer hoy día (Iradiel Murugarren, 1987, pp. 61-86; Cabré i Pairet, 2002, pp. 773-779 y Cabré i Pairet, 2008, pp. 171-208). Así ha quedado reflejado en las representaciones de miniados medievales, tratados médicos y recetarios. Desde etapas muy anteriores a la Edad Media, la cosmética y la perfumería han ostentado un claro protagonismo (Hamer Flores y Criado Vega, 2016, pp. 244-246). Por ejemplo, una tablilla asiria del siglo VIII ya menciona la

45 Siglos XV-XVI, BNE, Ms. 9226, fol. 118r.

46 1570, libro I, fol. 162r., Libro de los secretos del Reverendo don Alexo Piamontés. Versión de Toledo. 
combinación de un tanino y un sulfato de cobre o de hierro, afirmando que se puede utilizar para teñir el pelo de negro (Kroustallis, 2003, p. 581). Plinio el Joven aludía a la utilización de las agallas de roble para el tratamiento de la alopecia, indicando que debían mezclarse con grasa de oso para restaurar el cabello (Segura Munguía y Torres Ripa, 2009, p. 155).

Tanto recetas hispanas como europeas coinciden en utilizar la nuez de agalla como uno de los ingredientes principales para cuidar el cuerpo y la imagen. En términos generales, la función de esta materia prima reside en otorgar el color negro a cabellos y barbas, misma finalidad, como se ha plasmado en líneas anteriores, para la tinta de escribir y teñido de ciertos tejidos. Se ha documentado que, para eliminar las canas del cabello, se empleaban tintes negros obtenidos a partir de sales de plata o de plomo, azufre y lejías combinadas, componentes altamente dañinos para salud $^{47}$, pero poco a poco comenzaron a aplicar materias vegetales y naturales que no eran tan peligrosas, como el ácido de las agallas, yema de huevo, alumbre o hierbas aromáticas (Iradiel Murugarren, 1987, p. 75 y Criado Vega, 2011, p. 889). Todas las recetas analizadas para el caso de la Península Ibérica coinciden en que las agallas deben ser partidas o en forma de polvo y una vez hervido se aplicaba en la cabeza o barba, ya sea en solitario o con una amalgama junto al resto de ingredientes. Para el Ms. 8565 del siglo XV, existe un capítulo dedicado a teñir de negro el color blanco que produce las canas, tanto en cabellos como en barba. De las cinco recetas que incluye, en una se especifica que se añadan agallas de roble y zumaque porque "ayudan mucho a ennegrecer". Para conseguir ese color negro tan deseado, es necesario:

"las agallas anse de adresçar desta manera: quebrántense cada vna en quatro o cinco pedaços y hechense en remojo vna ora en aceite de aljonjolí e alegría e en manteca de bacas, después déjenlas secar e muélanse" ${ }^{48}$.

La misma receta se encuentra copiada en el capítulo 5 del Regalo de la vida humana de Juan Vallés, que posee varias sobre volver negros los cabellos canos y blancos de la cabeza y de la barba (Serrano Larráyoz, 2008, p. 288). Para esta ocasión, se explicita que se tomen cuatro onzas de agallas de Levante, se deben romper en tres o cuatro trozos y freírlas en aceite sin quemarlas. A continuación, se muelen con otras seis onzas de aciche (tierra de Sevilla) y todo esto convertido en polvo se arroja en nueve libras de lejía. El proceso, continua con otros ingredientes y el producto resultante es una tinta que, una vez lavado el vello con la lejía, podría aplicarse donde se desee. Después deben volver a utilizar lejía y agua tibia (Serrano Larráyoz, 2008, p. 289). El Ms. 2019 también proporciona una receta Para teñir los cabellos de blancos en muy buen negro y cuyas instrucciones y elementos empleados

47 Por ejemplo, consultar el Ms. 9226 de la BNE, fol. 67r. y ss.

48 Siglo XV, BNE, Ms. 8565, Vergel de señores, [e]n el cual se muestran a hazer con [mu]cha excelencia todas las conser[va]s, electuarios, confituras, turro[ne]s y otras cosas de azúcar y miel. Se muestran a hazer todos los a[fe]ytes, asi de olores como de medici[na]., fols. 130r-130v., cap. 4. 
son muy parecidos a la última receta de Juan de Vallés. Comienza indicando que se utilicen agallas de Levante o semejantes, se frían en una sartén para no quemarlas, después se muelen, se pasan por un cedazo y se le añade también cáscaras de granadas, nueces, piñones, mirra, hojas de Galecia, y todo junto molido, se hierve y se mantiene así hasta alcanzar la intensidad negra deseada. ${ }^{49}$ Entre las recetas que se conservan en la Biblioteca Colombina de Sevilla, en el Ms. 07-6-26 (Sala Hernando) hay una receta dedicada al teñido de negro de los cabellos, donde se recurría a acije (caparrosa), agallas, zumaque y pimienta. El modo de su fabricación sigue siendo el mismo reflejado en anteriores recetas, hervirlo y después lavar la cabeza. El único matiz es que añade también alumbre, como mordiente, para después hacer de nuevo un lavado con el tinte (Hamer Flores y Criado Vega, 2016, pp. 244-247). Todavía en el tránsito del siglo XVI al XVII existen recetas que mantienen el interés por teñir el cabello de negro con agallas, como la receta del Ms. 2019 que las mezcla con aceite ${ }^{50}$.

Por supuesto, existen otras preocupaciones con relación a la cosmética y el cabello, como es la alopecia. Hacia esta afección se encamina el códice Zabálburu en su receta para el cabello que se cahe de la cabeça. Recomienda que se lave la cabeza, una o dos veces por semana, con lejía fabricada con acelgas, camamilda (Manzanilla), zumaque, oruga, verdolagas y lechugas montesas. Una vez lavado el cabello con esto, se deben añadir polvos de agallas y con alheña, ambas molidas, aplicándose toda la noche y conservará el cabello (Pensado Figueiras, 2012, p. 164, núm. 2). Mismo enfoque presenta la receta del Ms. 8565, que ofrece una lejía de ceniza de cortezas de sarmiento, cortezas de avellanas, ramos de olivos, huesos de dátiles, asensios, alejandría, hojas y rábanos verdes de arrayán, simiente de ortigas, flor de romero, zumaque y agallas de roble para que nazcan, crezcan y no se caigan los pelos de la cabeza o barba ${ }^{51}$.

Todo lo anterior es similar en los manuscritos europeos, por ejemplo, Alejo Piamontés recoge una receta para teñir los cabellos y barbas blancas con agallas de Levante, las cuáles se han de hervir en aceite, moler y pasar por un cedazo ${ }^{52}$. En los secretos del libro de G. Rosetti muchos de los ingredientes citados en las recetas hispanas, vuelven aparecer, confluyéndose las agallas. Por ejemplo, posee dos recetas, una denominada Tintura negra per li capelli e barba, detallando la utilización de las agallas de Istria y su mezcla con aceite común, que debe hervir durante una hora (Rosetti, 1555, p. 35); y otra A fare li capelli negri que cita las agallas nuevamente junto con "ferrero di Spagna" (Rosetti, 1555, p. 46). Y vinculado con la estética bucal, también recoge en su interior una receta para blanquear los dientes, con cuerno de ciervo, cuerno de cabra y agallas (Rosetti, 1555, p. 63).

49 Siglos XV-XVI, BNE, Ms. 9226, fol. 67r.

50 Siglos XVI-XVII, BNE, Ms. 2019, fol. 2r.

51 Siglo XV, BNE, Ms. 8565, fols. 131r-131v., cap. 5.

52 1570, libro IV, fols. 105r.-105v., Libro de los secretos del Reverendo don Alexo Piamontés. Versión de Toledo. 


\section{CONCLUSIONES}

En definitiva, como se ha podido comprobar a través de los testimonios escritos de la época bajomedieval, el bosque ofrecía unos recursos naturales que iban más allá de los habitualmente conocidos. La explotación de la nuez de agalla en la España medieval estuvo muy extendida para multitud de aplicaciones y usos que manifiestan la importancia que tuvo, tanto para las distintas industrias como para la propia sociedad del momento. Las variedades de las agallas dependían de su procedencia geográfica (Turquía, Istria, Francia, Hungría, Flandes, Italia, España, Alepo, China, Rumanía, Túnez, Vallnegra, etc.) y sus características (blanca, negra, grosa, menuda, etc.). Recolectada de los árboles, normalmente de la familia Quercus, y originada a través de la picadura de determinados insectos, se podía recoger fácilmente y se convertía en un producto útil en el mercado.

En relación con su comercialización, llama poderosamente la atención que, a pesar de su alta utilización, como se ha comprobado en los recetarios, el resto de la documentación de la época no aporte apenas información más allá de las finalidades recogidas en este trabajo. Por ejemplo, no hay noticias sobre su recolección, cómo y cuándo debe ser recogida, si estaba o no protegida, por qué una variedad es mejor que otra y para qué finalidad o cómo conservarlas una vez manipuladas. Independientemente de la limitación de las fuentes escritas, posiblemente pudo tratarse de un recurso de consumo local o regional, pudiendo ser recogido por cualquier persona y convirtiéndose, en algunos casos, en una especie de economía familiar o complementaria a las actividades agroganaderas, como ocurre con la grana. Lógicamente esto sucedería en zonas donde predominara la agalla, quizás por esta circunstancia tiene dicha denominación la villa "Agallas" en la actualidad y aparecen las bolas de este recurso en su escudo. Esto puede explicar que su comercialización en el territorio de la Corona de Aragón fuese constante, pero nunca destacando sobre otros productos, igual que ocurre en las lezdas de la zona aragonesa o en el almojarifazgo de Chillón para el caso castellano. Además, se alude a esta materia vegetal en la documentación fiscal pero no en la compraventa de los Protocolos Notariales consultados hasta el momento. En cualquier caso, sí es posible afirmar que se importaba fundamentalmente del Mediterráneo Oriental, destacando Italia por las grandes cantidades que enviaba a través del Levante peninsular o la exportación desde Granada hacia Génova.

Por otra parte, con fortuna los recetarios de la época sí contribuyen al conocimiento del tratamiento y funciones que proporciona la agalla, dejando claro que los ácidos tánicos y gálicos de esta sustancia, eran idóneos para alcanzar el color negro en la fabricación de las tintas de escritura ferrogálicas. Precisamente, el deseo de obtener dicha tonalidad es lo que convierte a la agalla vegetal en un valioso ingrediente en otros sectores y aplicaciones, como el curtido de pieles y el teñido de diferentes tejidos y el tinte para cabellos y barbas para ocultar el blanco de las 
canas. Sin embargo, sus propiedades astringentes también hicieron de este recurso natural un elemento imprescindible de los compuestos médicos, farmacológicos y cosméticos. Se trata de un producto básico que satisface una demanda globalizada, para la producción de los artesanos, pero también para una persona que estuviera en su hogar y deseara cuidar su aspecto, ya sea cuidando sus dientes, combatiendo la calvicie o tiñendo la barba o los cabellos. Una materia prima poco conocida hoy día, pero muy vinculada con mujeres y hombres del período medieval que la aprovechaban asiduamente en su vida cotidiana.

\section{REFERENCIAS BIBLIOGRÁFICAS}

Airaldi, G. (1966). Genova e Spagna nel secolo XV. Il liber damnificatorum in regno Granate (1452). Génova, Italia: Universidad de Génova.

Alomar i CANYelles, A. (2002). Dos inventaris d'apotecaria del segle XIV. Gimbernat: Revista d'Història de la Medicina y de les Ciències de la Salut, vol. 37, 83-111. ARVIDE CAMBRA, M ${ }^{a}$ L. (1993). Un ejemplo de medicina práctica en Al-Andalus: El Kztab Mujarrabat al-Jawag de Abü-l- 'Ala' Zuhr (c. 1060- 1131). Dynamis: Acta hispánica ad medicinae scientiarumque historiam illustrandam, (13), 295-346.

Caballero Navas, C. (2006). Algunos 'secretos de mujeres' revelados. El Še'arb Yašub y la recepción y transmisión del Trotula en hebreo. MEAH, sección Hebreo $55,381-425$.

Cabanes Catalá, M. L. (2007) (Coord.). Libro de los Oficios del Monasterio de Nuestra Señora de Guadalupe (2 vols.). Madrid y Mérida, España: Secretaria General Técnica del Ministerio de Cultura, Subdirección General de Publicaciones, Información y Documentación, Junta de Extremadura, Consejería de Cultura y Turismo y Monasterio de Guadalupe.

CABRÉ i PAiret, M. (2002). Cosmética y perfumería. En L. García Ballester (Coord.), Historia de la ciencia y de la técnica en la Corona de Castilla. II: Edad Media (pp. 773-779). Valladolid, España: Junta de Castilla y León.

CABRÉ I PAiRet, M. (2008). Los consejos para hermosear ("libros" I-III) en el Regalo de la vida humana de Juan Vallés. En J. Vallés, Regalo de la vida humana. Estudios y transcripción (pp. 171-208). Transcripción del manuscrito y coordinación de estudios F. Serrano Larráyoz. Pamplona, España: Gobierno de Navarra y Austria: Österreichische Nationalbibliothek.

CABRERA MUÑOZ, E. (2002). El bosque, el monte y su aprovechamiento en la España del Sur durante la Baja Edad Media. En F. J. Pérez-Embid Wamba (Ed.), La Andalucía Medieval: actas de las I Jornadas de Historia Rural y Medio Ambiente (pp. 249-272). Huelva, España: Universidad de Huelva.

Carabaza Bravo, J. Ma (1999). Algunos arabismos en la traducción del kitab fi adab al-hisba de al-saqati (II). En E. M. Tawfik Aly y J. Ma Carabaza Bravo (Eds.). El 
saber en Al-Andalus. Textos y estudios, II (pp. 29-44). Sevilla, España: Universidad de Sevilla y Fundación El Monte.

CÁrcel Ortí, Ma M. y Trenchs Odena, J. (1979). La tinta y su composición. Cuatro recetas valencianas (siglos XV-XVIII). Revista de Archivos, Bibliotecas y Museos, (82), 415-426.

CARmona Ruiz, Ma A. (2011). El aprovechamiento de los espacios incultos en la Andalucía Medieval: el caso de la Sierra Norte de Sevilla. En E. Martín Gutiérrez (Edit.). El paisaje rural en Andalucía Occidental durante los siglos bajomedievales: actas de las I Jornadas Internacionales sobre paisajes rurales en época medieval (pp. 193-208). Cádiz, España: Universidad de Cádiz.

Cavacciochi, S. (ed.) (2002). L'uomo e la foresta, secc. XIII-XVIII. Florencia, Italia: Instituto Internacional de Historia Económica "F. Datini" (Atti della 34 settimana di studi).

Cifuentes i Comamala, L. y CóRdoba de la LlaVe, R. (2011). Tintorería y medicina en la Valencia del siglo XV: el manual de Joanot Valero. Madrid, España: CSIC.

Clemente Ramos, J. (Ed.) (2001). El medio natural en la España medieval. Actas del I Congreso sobre Ecohistoria e Historia Medieval. Cáceres, España: Universidad de Extremadura.

Clemente Ramos, J. (2001). El medio natural en Extremadura (c. 1142-c. 1525). En J. Clemente Ramos (Ed.), El medio natural en la España medieval. Actas del I Congreso sobre Ecohistoria e Historia Medieval (pp. 15-56). Cáceres, España: Universidad de Extremadura.

CONTRERAs-Zamorano, G. M ${ }^{a}$ (2015). La tinta de escritura en los manuscritos de archivo valencianos, 1250-1600. Análisis, identificación de componentes y valoración de su estado de conservación. Tesis doctoral dirigida por A. Serra, V. Pons y D. Juanes. Valencia, España: Universitat de Valencia, Departamento de Historia del Arte.

Córdoba de la Llave, R. (1990). La industria medieval de Córdoba. Córdoba, España: Montes de Piedad y Caja de Ahorros.

CóRdoba de la Llave, R. (2002). Las técnicas pre-industriales. En L. García Ballester (Coord.), Historia de la ciencia y de la técnica en la Corona de Castilla. II: Edad Media (pp. 221-432). Valladolid, España: Junta de Castilla y León.

CóRdoba de la LlaVe, R. (2005). Un recetario técnico castellano del siglo XV: el manuscrito H-490 de la Facultad de Medicina de Montpellier. En la España Medieval, (28), 7-48.

Cóndoba de la Llave, R. (2012). Las rasuras del vino. Aplicaciones y usos del tartrato de potasio en la España bajomedieval. En Mundos medievales: espacios, sociedades y poder. Homenaje a J. A. García de Cortázar y Ruiz de Aguirre, 2 vols. (vol. II, pp. 1189-1200). Cantabria, España: Universidad de Cantabria. 
CRiado Vega, T. Ma (2011). Las artes de la paz. Técnicas de perfumería y cosmética en recetarios castellanos de los siglos XV y XVI. Anuario de Estudios Medievales, 41 (2), 865-897. https://doi.org/10.3989/aem.2011.v41.i2.374

CRiado Vega, T. Ma . (2013). Tratados y recetarios de técnica industrial en la España medieval. La Corona de Castilla, siglos XV-XVI. Tesis doctoral dirigida por R. Córdoba de la Llave. Córdoba, España: Universidad de Córdoba, Departamento de Ciencias de la Antigüedad y Edad Media.

DARWIN, Ch. (2008). La variación de los animales y las plantas bajo domesticación, traducción e introducción de A. García González. Madrid, España: CSIC.

De Hamel, Ch. (2001). Artesanos medievales. Copistas e iluminadores. Madrid, España: Akal.

De los Santos Rodríguez, R. M. y SuÁrez Smith, C. (1997). Informe técnico sobre los trabajos de conservación y restauración de la capa del infante don Felipe (siglo XIII). Boletín del Museo Arqueológico Nacional, 15 (1-2), 231- 240.

De SeVILla, San Isidoro (2004). Etimologías. Texto latino, versión española y notas por J. Oroz Reta y M. Marcos Casquero. Madrid, España: Biblioteca de Autores Cristianos.

DiosCóRIDES (1998). Plantas y remedios medicinales (De materia médica), libros I-III. Introducción, traducción y notas de Manuela García Valdés. Madrid, España: Gredos.

Dorini, U. y BertelĖ, T. (1956). Il Libro dei conti di Giacomo Badoer. Roma. Italia: Instituto Poligrafico dello stato.

DurÁn i Duelt, D. (2008). Els mallorquins a la Romania (segles XIII-XVI). En M. Barceló Crespí (Ed.), El Regne de Mallorca: cruïlla de gents i de cultures (segles XIII-XV): XXVI Jornades d'Estudis Històrics Locals (pp. 241-255). Palma. España: Institut d'Estudis Baleàrics.

Edelstein, S. M. y Borghetty, H. C. (1969). The Plictho og Gioanventura Rosetti. Instructions of the Art of the Dyer which teaches the dyeing of woolen, cloths, linens, cottons and silk by the great art as well as by the common. Cambrigde, Londres, Inglaterra; Massachusetts, EEUU: M.I.T. Press y Massachusetts Institute of Technology.

García de Cortázar, J. A. (2002). Sociedad rural y medio físico en la España Medieval: Transformaciones del entorno físico en el Reino de Castilla en los siglos VIII al XV. En F. J. Pérez-Embid Wamba (Ed.), La Andalucía Medieval: actas de las I Jornadas de Historia Rural y Medio Ambiente (pp. 15-42). Huelva, España: Universidad de Huelva.

García de CortázAr, J. A. (2007). Sociedad rural y entorno-físico: las modificaciones del paisaje en la Castilla medieval. En F. Sabatell (Coord.), Natura I desenvolupament: el medi ambient a l'Edat Mitjana (pp. 251-274). Lleida, España: Pagès Editors. 
García Marsilla, J. V. (2017). Los colores del textil. Los tintes y el teñido de los paños en la Valencia medieval. En G. Castelnuovo y S. Victor (Eds.), L'histoire à la source: acter, compter, enregistrer (Catalogne, Savoie, Italie, XIIe-XVe siècle): mélanges offerts à Christian Guilleré. Chambéry y Saboya (pp. 283-315). Francia : Université Savoie Mont Blanc y UFR Lettres, Langues, Sciences Humaines Laboratoire Langages, Littératures, Sociétés.

GrÉGORIE, L. y Desplats, V. A. (1894). Diccionario enciplopédico de Ciencias, Literatura y Artes. París, Francia: Garnier hermanos, Libreros-Editores.

Gual Camarena, M. (1976). Vocabulario del comercio medieval: colección de aranceles aduaneros de la Corona de Aragón (siglos XIII y XIV). Barcelona, España: Ediciones El Albir S.A.

Gual Camarena, M. (1981). El primer manual hispánico de mercadería (siglo XIV). Barcelona, España: CSIC.

GONZÁLEZ JimÉNEZ, M. et alii. (2016). El libro primero de ordenanzas del concejo de Córdoba. Edición y estudio crítico. Madrid, España: Compobell y SEEM.

Hamer Flores, A. y Criado Vega, T. (2016). Belleza y salud a fines de la Edad Media. Las recetas castellanas de los manuscritos de Hernando Colón. Historia. Instituciones. Documentos, (43), 243-260.

HeRnández Vegas, M. (1935). Ciudad Rodrigo. La Catedral y la ciudad. 2 vols. Salamanca: Imp. Comercial Salmantina.

HIPÓCRATES (1993). Tratados Hipocráticos VIII. Tratados quirúrgicos. Madrid, España: Gredos.

IRADIEL MURUgarRen, P. (1974). Evolución de la industria textil castellana en los siglos XIII-XVI. Factores de desarrollo, organización y costes de la producción manufacturera en Cuenca. Salamanca, España: Universidad de Salamanca.

IRAdiel Murugarren, P. (1987). Cuidar el cuerpo, cuidar la imagen: los paradigmas de la belleza femenina en la Valencia bajomedieval. En Les soins de beauté. Moyen Âge, début des temps modernes. Actes du IIIe Colloque International Grasse (26-28 avril, 1985) (pp. 61-86). Niza, Francia : Université de Nice.

Kroustallis, S. (2002). Escribir en el siglo XVI: recetas de tinta negra española. Torre de los Lujanes. Revista de la Real Sociedad Económica Matritense, (48), 99112.

Kroustallis, S. (2003). La tinta negra ferrogálica. A propósito de sus fuentes. En $V$ Congreso Nacional de Historia del Papel en España (pp. 579-584). Girona, España: Ayuntamiento de Sarrià de Ter.

KROUSTALlis, S. (2008). La escritura y sus materiales: pigmentos, tintas e instrumentos. En El soporte de la lengua (pp. 133-166). Nájera, España: Patronato Santa María la Real de Nájera, Ministerio de Cultura e Instituto del Patrimonio Histórico Español. 
LÓPEZ Rider, J. (2016). La producción de carbón en el reino de Córdoba a fines de la Edad Media: un ejemplo de aprovechamiento del monte mediterráneo. Anuario de Estudios Medievales, 46 (2), 819-858.

LÓPEZ RIDER, J. (2018). The vegetal landscape of the southwest of Cordoba: a sample of the natural environment of Andalusia in the Late Middle Ages. Journal of Medieval Iberian Studies, 10 (3), 364-384.

Maíllo SAlgado, F. (1998). Los arabismos del castellano en la Baja Edad Media. Salamanca, España: Universidad de Salamanca.

Manual de Mugeres en el qual se contienen muchas y deversas reçeutas muy buenas (1995). Estudio, edición y notas, a cargo de A. Martínez Crespo. Salamanca, España: Universidad de Salamanca, Textos recuperados.

MARTín GutiÉRREZ, E. (2011). El paisaje rural en Andalucía Occidental durante los siglos bajomedievales: actas de las I Jornadas Internacionales sobre paisajes rurales en época medieval. Cádiz, España: Universidad de Cádiz.

Melis, F. (1972). Documenti per la storia economica dei secoli XIII-XVI. Florencia. Italia: L. S. Olschki.

Merrifield, M. (1967). Medieval and Renaissance Treatises on the arts of Painting, Original Texts with English Translations. Nueva York, EEUU: Dover Publications.

NAvArro Espinach, G. (2009). Los aranceles del Peaje de Zaragoza de 1292. En J. A. Sesma Muñoz y C. Laliena Corbera (Coords.), Crecimiento económico y formación de los mercados en Aragón en la Edad Media (1200-1350) (pp. 411-426). Zaragoza, España: C.E.M.A. y Universidad de Zaragoza.

NieVes-Aldrey, J. L. (1998). Insectos que inducen la formación de agallas en las plantas: una fascinante interacción ecológica y evolutiva. Boletín SEA, (23), 3-12.

ORLANDI, A. (2008). Mercaderies i diners: la correspondència datiniana entre València i Mallorca (1395-1398). Valencia. España: Universitat de Valencia.

Pensado Figueiras, J. (2012). El códice Zabálburu de medicina medieval: edición crítica y estudio de fuentes. Tesis doctoral dirigida por A. Ferraces Rodríguez. La Coruña, España: Universidade da Coruña, Departamento de Filoloxía Española y Latina.

PÉREZ-EMbid WAmbA, F. J. (Ed.) (2002). La Andalucía Medieval: actas de las I Jornadas de Historia Rural y Medio Ambiente. Huelva, España: Universidad de Huelva.

Pifarré Torres, D. (2002). El comerç internacional de Barcelona i el Mar del Nord, Bruges, a finals del segle XIV. Barcelona. España: L'Abadia de Montserrat.

Pomaro, G. (1991). I ricettari del fondo Palatino della Biblioteca Nazionale Centrale di Firenze. Milán, Italia: Giunta Regionale Toscana/Editrice Bibliografica, Milán.

Rebora, G. (1970). Un manuale di tintoria del Quattrocento. Génova, Italia: Università degli studi di Genova, Istituto di storia economica.

Recio Muñoz, V. (2016). La Practica de Plateario. Edición crítica, traducción y estudio. Florencia, Italia: SISMEL, Edizioni del Galluzzo. 
Recopilación de las ordenanzas de la muy noble e muy leal cibdad de Sevilla (1527, reimpresión, 1975). Sevilla, España: Juan Varela de Salamanca.

Rosetti, G. (1555). Notandissimi secreti de l'arte profumatoria, per fare ogli, acque, paste, balle, moscardini, uccelletti, paternostri, e tutta l'arte initiera, come si ricerca cosi nella citta di Napoli del Reame, come in Roma, e quivi in la citta di Vinegia nuevamente impresi. Venecia, Italia: Francesco Rampazetto.

SAladrigas ChenG, S. (1996). Los tejidos en Al-Andalus: siglos IX-XVI. Aproximación técnica. En España y Portugal en las rutas de la seda: diez siglos de producción y comercio entre Oriente y Occidente (pp. 74-98). Barcelona, España: Universitat Autònoma de Barcelona.

SALICRÚ I LLUCH, R. (1995). El tràfic de mercaderies a Barcelona segons els comptes de la lleuda de Mediona (Febrer de 1434) (I), Barcelona, España: CSIC, Institució Milà i Fontanals.

Segura Munguía, S. y Torres Ripa, J. (2009). Historia de las plantas en el mundo antiguo. Madrid y Bilbao, España: CSIC y Universidad de Deusto.

SESMA MuÑOZ, J. A. (2001). El bosque y su explotación económica para el mercado en el sur de Aragón en la Baja Edad Media. En J. Clemente Ramos (Ed.), El medio natural en la España medieval. Actas del I Congreso sobre Ecohistoria e Historia Medieval (pp. 195-213). Cáceres, España: Universidad de Extremadura.

Smith, C. S. y Hwathorne, J. G. (1974). Mappae Clavicula, A little key to the World of Medieval Techniques (Vol. 4, part. 64). Filadelfia, EEUU: American Philosophical Society. https://doi.org/10.2307/1006317

TeOfRasto (1988). Historia de las plantas. Edición y traducción de J. Mª Díaz- Regañón López, Madrid, España: Gredos.

Trillo SAN JosÉ, Ma del C. (1996). Los aranceles de la ciudad de Granada a final de la Edad Media. Arqueología y territorio medieval, (3), 253-272. https://doi.org/10.17561/aytm.v3i0.1631

VALLÉS, J. (2008). Regalo de la vida humana (2 vols.). Transcripción del manuscrito y coordinación de estudios F. Serrano Larráyoz. Pamplona, España: Gobierno de Navarra y Austria: Österreichische Nationalbibliothek.

VÁzQuez DE BEnito, C. y Bustos, T. de (1997-1998). Recetario morisco médicohipiátrico. Sharq al-Andalus, (14-15), pp. 375-462.

https://doi.org/10.14198/ShAnd.1997-1998.14-15.18

Vignet ZunZ, J. y Ortega SAntos, A. (Coords.) (2003). Las montañas del Mediterráneo: coloquio internacional celebrado en Granada (4-6 de febrero de 1999). Granada, España: Centro de Investigaciones Etnológicas Ángel Ganivet.

Zerdoun Bat-Yehouda, M. (1983). Les encres noires au moyen age. París, Francia: Centre national de la recherche scientifique. 